\title{
The Frequency and Distribution of Female Genital Tract Malignancies in a Multispecialty Hospital in Delhi
}

\author{
Qury Sabita Mahapatra ${ }^{1}$, Sangeeta Lamba ${ }^{2}$, Annu Nanda ${ }^{1 *}$, Divya Sethi ${ }^{2}$ and Sonam L. Jain ${ }^{2}$ \\ 'Department of Pathology, ESIC Dental College \& Hospital, Rohini, Delhi, India \\ ${ }^{2}$ Department of Pathology , ESI Hospital, Rohini, Delhi,India
}

\begin{abstract}
Background: The most common malignancy in women is breast carcinoma worldwide. However cancers of the female genital tract are still an important cause of cancer morbidity and mortality. They are the next commonest malignancy after breast cancer in women.

Aim: A hospital based study was conducted to determine the type and frequency of genital tract malignancies in women in multispecialty hospital in Delhi

Material and Methods: Data from records of surgical biopsy \& resection specimens along with demographic data for $3 y r s$ of all the female patients with malignant lesions were included in the study. The distribution and prevalence of malignancies of female genital tract were analyzed.

Results: A total of 118 female patients diagnosed with malignancy were included in this study. Of these 50 cases had breast carcinoma, 48 cases had carcinoma of genital tract and 20cases had others including carcinoma of oral cavity, salivary gland, thyroid, lymphomas, and GIT carcinoma. Cervical carcinoma (83.3\%) was the most common gynecological malignancy followed by the ovary (10.4\%) $\&$ then endometrial carcinoma (6.25\%). Most common age group affected by cervical carcinoma was 51-60yrs. Moderately differentiated squamous cell carcinoma was the most common grade of cervical carcinoma noted.

Conclusion: Cervical carcinoma was the most common gynecological malignancy in our study. Efforts should be made to reduce cancer burden by focus on health education of the masses, routine screening programmes for detection of cancers in females \& establishing centres for monitoring \& evaluation of these programmes.
\end{abstract}

Keywords: : Female Genital Tract, Malignancy, Prevalence

\section{Introduction}

The occurrence of cancer continues to increase across the globe and it is a leading cause of death worldwide. It is estimated that 7.6million people died of carcinoma in 2008. ${ }^{[1]}$

The most common malignancy worldwide in women is carcinoma of breast, representing nearly a quarter [25\%] of all cancers with estimated 1.67 million new cases diagnosed in 2012. ${ }^{[2]}$ Around 70,000 new cases of uterine cancers and 75,000 new cases of carcinoma breast are reported in India every year. ${ }^{[3]}$ In India gynecological cancers account for 10$15 \%$ of all cancers diagnosed each year and cancer cervix is the most common gynecological malignancy noted. ${ }^{[4]}$ Earlier cervical cancer was the most common cancer in Indian women but now breast carcinoma has surpassed it $\&$ is the leading cause of cancer related death. ${ }^{[5]}$ Carcinoma cervix still remains commonest malignancy in females in rural India. ${ }^{[5]}$

The aim of this study was to determine the frequency of genital tract malignancies in Indian women.

\section{Material and methods}

A hospital based study was conducted in a multispecialty hospital, Delhi analyzing the patient records for last 3 years from $1^{\text {st }}$ January 2015 to $31^{\text {st }}$ December 2017 . Women with malignant lesions were included in the study \& information about the age; site and clinical presentation were obtained from the requisition forms. Results were categorized, as frequency of malignancies seen in the females, with major focus given to distribution and histopathology of malignancies of female genital tract.

\section{Results}

Out of the 118 female patients with malignant tumors, 50 [42.3\%] had breast carcinoma, 48[40.7] patients had genital tract carcinoma and 20[16.9] had others including carcinoma of oral cavity, salivary gland, thyroid, lymphomas, and GIT carcinoma. [Table 1]. Carcinoma breast was the commonest malignancy noted in this study. The most common genital tract malignancy was carcinoma cervix,[83.3\%] followed by ovary[10.4\%] and endometrium [6.25\%].[Table 2] 
Commonest age of presentation of carcinoma cervix was in the age group 51-60yrs. None of the cases were seen before 30yrs of age.[Table3] Cases with cervical carcinoma presented with post menopausal bleeding, and/or mass in the cervical region. Moderately differentiated squamous cell carcinoma was the most common grade of cervical carcinoma noted.

\section{Discussion}

Breast carcinoma was the most common carcinoma noted in this study. [42.3\%] It has emerged as the commonest malignancy in the urban female population of India. ${ }^{[6]}$ As per the ICMR-population Based Cancer Registry (ICMRPBCR) data, breast cancer is the commonest cancer among urban registries in Delhi, Mumbai, Ahmadabad, Calcutta, $\&$ Trivandrum $^{[7]}$ In our study it constitutes $>40 \%$ of all cancers in females.

Cancer of the cervix has been the most common cancer among women in the past two decades. ${ }^{[8]}$ According to our study, cancer cervix $(83.33 \%)$ was the major cause of genital malignancy. This is in accordance with other studies where $80 \%$ cases were reported in India ${ }^{[9]}$ and

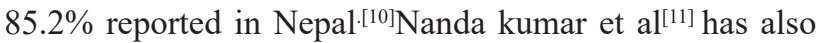
reported cervical cancer to be the commonest cancer amongst females. Megafu et al reported an incidence of $73.1 \%$ cases of cervical cancer among all genital tract malignancy in their study. ${ }^{[12]}$ Cancer cervix incidence varies with geographical region and ethnicity. ${ }^{[13]}$ India also has the highest age standardized incidence of cervical cancer in South Asia at 22, compared to 19.2 in Bangladesh, 13 in Sri Lanka, and 2.8 in Iran. ${ }^{[14]}$

Epidemiological studies have consistently indicated that the risk of cervical cancer is strongly influenced by measures of sexual activity. ${ }^{[15]}$ In India, HPV 16, 18, 31, 33 and 45 account for $>92 \%$ of the squamous cell carcinomas and $95 \%$ of the cervical adenocarcinomas ${ }^{[16]}$ Risk factors of HPV infection are multiple sexual partners, early marriage and early sexual activity, high parity, cigarette smoking, poor hygiene, oral contraceptives and immunodeficiency states, e.g. HIV infection. ${ }^{[15]}$ The higher incidence of cervical cancer in our study may be due to early marriage

Table 1: Site wise distribution of cancers in females.

\begin{tabular}{|c|c|c|}
\hline Site of cancer & Numberof cases & percentage \\
\hline Breast & 50 & 32.37 \\
\hline Cervix & 40 & 33.9 \\
\hline Ovary & 05 & 2.24 \\
\hline Endometrium & 03 & 16.95 \\
\hline $\begin{array}{c}\text { Oral cavity, salivary gland, Thyroid, GIT } \\
\text { carcinoma, Lymph node malignancy }\end{array}$ & 20 & \\
\hline Total & 118 & \\
\hline
\end{tabular}

Table 2: Site wise distribution of cancers of female genital tract.

\begin{tabular}{|c|c|c|}
\hline Site of tumor & Number of cases & Percentage \\
\hline Cervix & 40 & 10.43 \\
\hline Ovary & 05 & 06.25 \\
\hline Endometrium & 03 & \\
\hline Vulva ,Vagina, Fallopian tube & NIL & \\
\hline Total & $\mathbf{4 8}$ & \\
\hline
\end{tabular}

Table 3: Age distribution in the different malignant tumors of female genital tract:

\begin{tabular}{|c|c|c|c|c|c|c|}
\hline \multirow[t]{2}{*}{ Age (yr) } & \multicolumn{2}{|c|}{ Cervix } & \multicolumn{2}{|c|}{ Ovary } & \multicolumn{2}{|c|}{ Uterus } \\
\hline & Number & Percentage & & & & \\
\hline $21-30$ & - & & 1 & 20 & - & - \\
\hline $31-40$ & 03 & 07.5 & - & - & 1 & $33.33 \%$ \\
\hline $41-50$ & 09 & 22.5 & 2 & 40 & 1 & $33.33 \%$ \\
\hline $51-60$ & 16 & 40 & 2 & 40 & 1 & $33.33 \%$ \\
\hline $61-70$ & 12 & 30 & - & & & \\
\hline Total & 40 & 100 & 5 & 100 & 3 & \\
\hline
\end{tabular}


and early sexual activity ,high parity ,poor hygiene or a lack of knowledge about the methods for cervical cancer screening of the masses. Cervical cancer screening is an important tool in prevention \& early treatment because of window of opportunity during longstanding pathogenesis of cervical cancer. ${ }^{[17]}$ Lack of organized mass screening programmes for early detection of cervical cancer is a contributing factor towards high cervical cancer incidence in our population.

Majority of patients with cancer cervix presented in advanced age group. Only 3 cases [7.5] were seen in the age group of 31-40yr, and reached peak in 51-70yrs [28/40] $(70 \%)$. Similar results were seen by other authors ${ }^{[18][19]}$ As cervical cancer progresses slowly from precancerous conditions to advanced cancer, the incidence increases beyond 35yrs of age and reaches a maximum in women in $6^{\text {th }}-7^{\text {th }}$ decade. ${ }^{[20]}$

Most common clinical presentation of cervical tumors in our study was postmenopausal bleeding followed by mass in the cervical region. The commonest histopathological type of cervical cancer was squamous cell carcinoma and this was followed by adenocarcinoma. The trend is similar to other studies. ${ }^{[15][18][21]}$

According to our study ovarian cancer was the $2^{\text {nd }}$ most common genital tract tumor [10.41\%] followed by endometrial ca [6.25\%]. This pattern of distribution was different from that of developed countries where ovarian cancer was the leading genital cancer .Serous cyst adenocarcinoma was the commonest cancer encountered by us as well by others, ${ }^{[15]}$ whereas Ahmed et al ${ }^{[22]}$ found mucinous cyst adenocarcinoma to be the commonest ovarian tumor. Among the gynecological malignancies, ovarian cancer is the most sinister lesion due to its late detection owing to inaccessible location of ovary \& absence of standard methods of screening for ovarian cancer. ${ }^{[23]}$

Endometrial malignancies constituting $6.3 \%$ of all gynecological malignancies were the third most common genital tract malignancy noted in this study. This is in accordance with many studies. ${ }^{[20]}$ There is no good screening test for endometrial carcinoma. However, ultrasound to detect endometrial thickness ${ }^{[24]}$ and measurement of endometrial volume ${ }^{[25]}$ can be used to predict malignancy.

There were no cases of tubal, vaginal or vulval malignancies in the current study. It correlated with other studies as primary tumors of vagina, ${ }^{[26]}$ vulva and tubes are rare.

\section{Conclusion}

Cancers of female reproductive tract and breast are common in Indian women. Cervical cancer was the most common gynecological malignancy noted in our study. In India inspite of introduction of pap screening programmes for early detection of cancer cervix, majority of women are still ignorant of its importance. A concerted effort should be done towards prevention of these cancers, by creating awareness through health education in addition to implementation of screening methods

\section{Reference}

1. Ferly J, Shin HR, Bray F, Forman D, Mathers C, Parkin DM. GLOBOCAN 2008 v2.0. Cancer incidence and mortality worldwide: IARC Cancer Base No.10. Available from: http://globocan.iarc.fr

2. Ferlay J, Soerjomataram I, Diskshit R, Eser S, Mathers C, Rebelo M, et al.Cancer Incidence and Mortality Worldwide: sources, methods and major patterns in GLOBOCAN 2012 Int J Cancer 2015;136:359-86.

3. Devi KU. Current status of gynaecological cancer care in Indian J Gynecol Oncol 2009;2:77-80.

4. Basile S, Angioli R, Manci N, Palaia I, Plotti F, Benedetti panici P. Gynecological cancers in developing countries: The challenge of chemotherapy in low-resource setting. Int J Gynecol Cancer 2006;16:1491-7.

5. Kaarthigeyan K. Cervical cancer in India and HPV vaccination. Indian J Med Paediatr Oncol 2012; 33: 7-12.

6. National Cancer Registry Program . Ten year consolidated report of the Hospital Based Cancer Registries, 1984-1993, an assessment of the burden and care of cancer patients. New Delhi: Indian Council of Medical Research; 2001.

7. Agarwal G, Ramakant P. Breast cancer care in India. The Current Scenario \& the Challenges for the Future. Breast care $2008 ; 3: 21-7$.

8. Nandakumar A, Ramnath T, Chaturvedi M. The magnitude of cancer cervix in India. Indian J Med Res 2009; 130:219-21

9. Chhabra S, Sonak M, Prem V, Sharma S. Gynaecological malignancies in a rural institute in India. J Obstet Gynaecol 2002; 22: 426-9.

10. Dhakal HP, Pradhan M. Histological pattern of gynaecological cancers. J Nepal Med Assoc 2009; 48:301-5.

11. Nandakumar A, Anantha N, Dhar M, Ahuja V, Kumar R, Reddy S, et al. A case control investigation of cancer of the ovary in Bangalore, India. Int J Cancer 1995;63:361-5.

12. Megafu U. Cancer of genital tract among Ibo women in Nigeria. Cancer 1979;44:1875-8.

13. Rastogi T, Devesa S, Mangtani P, Mathew A, Cooper N, Kao R, et al. Cancer incidence rates among South Asians in four geographic regions:India, Singapore, UK and US. Int J Epidemiol 2008; 37:147-60.

14. ICO Information Centre on HPV and cancer (Summary Report 2014-08-22).Human Papillomavirus and Related Diseases in India. 2014 
15. Ellenson LH, Pirog EC. The Female Genital Tract.In: Robbins and Cotran Pathologic basis of disease.8th edn. Philadelphia: Elsevier Saunders, 2010; 1005-63.

16. Paavonen J, Naud P, Salmeron J, Wheeler CM, Chow SN, Apter D etal. Efficacy of the human papillomavirus (HPV)16/18 AS04-adjuvanted vaccine against cervical infections and pre-cancer which are caused by the oncogenic HPV types (PATRICIA): final analysis of a doubleblind, randomised study in young women. Lancet 2009;25:301-14.

17. Cole P, Morrison AS. Basic issues in population screening for cancer. J Natl Cancer Inst 1980;6:1263-72.

18. Jamal S, Mamoon N, Mushtaq S, Luqman M, Moghal S. The pattern of gynecological malignancies in 968 cases in Pakistan. Ann Saudi Med 2006; 26:382-4.

19. Okeke TC, Onah N, Ikeako LC, Ezenyeaku CCT.The frequency and pattern of female genital tract malignancies at the University of Nigeria Teaching Hospital, Enugu, Nigeria. Ann Med Health Sci Res 2013; 3:345-8.

20. Jacques Ferlay, et al., GLOBOCAN 2002: Cancer Incidence, Mortality and Prevalence Worldwide, IARC Cancer Base No. 5, version 2.0 (Lyon, France:IARC, 2004).
21. Talukder SI, Haque MA, Alam MO, Huq MH,Roushan A, Jahan MK, et al. Gynaecological cancers in surgical specimens in Mymensingh,Bangladesh, 2006. Bangladesh J Pathol 2008;23:2-4.

22. Ahmad Z, Kayani N, Hasan SH. Histological pattern of ovarian neoplasm. J Pak Med Assoc 2000;50:416-9.

23. Miller BE. Ovarian Cancer In: Ling FW, Duff P, editors. Obstetrics and gynecology principles for practice, New York:McGraw-Hill Companies; 2001. p. 1298-314

24. Epstein E, Valentin L. Rebleeding and endometrial growth in women with postmenopausal bleeding and endometrial thickness less than $5 \mathrm{~mm}$ managed by dilatation and curettage or ultrasound follow up: a randomized controlled study. Ultrasound Obstet Gynaecol 2001;18:499-504.

25. Khursheed F, Jatoi N, Das CM. Genital tract malignancies in postmenopausal women. J Ayub Med Coll Abbottabad 2010;22:32-4.

26. Seleye-Fubara-D, Uzoigwe SA, Akani CI. Pathology of vaginal cancers in Port Harcourt, Nigeria. A 14-year study. Niger J Clin Pract 2007;10:330.

*Corresponding author:

Dr Annu Nanda, Professor \& HOD, Department of Pathology, ESIC Dental College \& Hospital, Rohini, Sector -15, Delhi, India 110085

Phone: +91 8527056360

Email: annunanda@rediffmail.com

Financial or other Competing Interests: None. 